Georgetown University Law Center

Scholarship @ GEORGETOWN LAW

2009

\title{
Chronicling the Complexification of Negotiation Theory and Practice
}

Carrie Menkel-Meadow

Georgetown University Law Center, meadow@law.georgetown.edu

This paper can be downloaded free of charge from:

https://scholarship.law.georgetown.edu/facpub/29

25 Negotiation J. 415-429 (2009)

This open-access article is brought to you by the Georgetown Law Library. Posted with permission of the author. Follow this and additional works at: https://scholarship.law.georgetown.edu/facpub

Part of the Dispute Resolution and Arbitration Commons, Legal Education Commons, and the Public Law and Legal Theory Commons 


\title{
GEORGETOWN LAW Faculty Publications
}

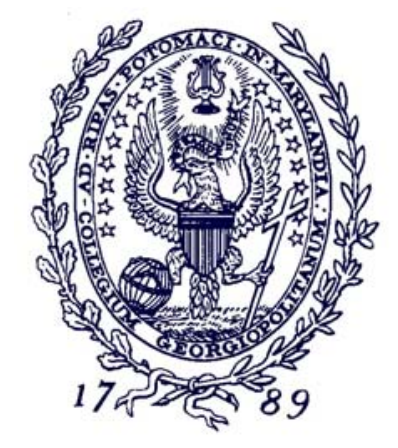

November 2009

\section{Chronicling the Complexification of Negotiation Theory and Practice}

25 Negotiation J. 415-429 (2009)

\author{
Carrie Menkel-Meadow \\ Professor of Law \\ Georgetown University Law Center \\ meadow@law.georgetown.edu
}

This paper can be downloaded without charge from:

Scholarly Commons: http://scholarship.law.georgetown.edu/facpub/29/

SSRN: http://ssrn.com/abstract $=1500645$

Posted with permission of the author 


\title{
Special Section: Negotiation Journal Looks Back on Twenty-Five Years of Negotiation Theory, Research, Practice, and Teaching \\ Chronicling the Complexification of Negotiation Theory and Practice
}

\author{
Carrie Menkel-Meadow
}

The essay reviews the content of twenty-five years of Negotiation Journal, identifying themes and issues explored on its pages in the past, the current issues challenging the field's scholars and practitioners,

Carrie Menkel-Meadow is A. B. Chettle, Jr. Professor of Law, Dispute Resolution, and Civil Procedure at Georgetown University Law Center and Founding Faculty, University of California, Irvine School of Law. For 2009-2010, she will also serve as the faculty director of the Center for Transnational Legal Studies in London. Her e-mail address is meadow@law.georgetown.edu. 
and the issues likely to confront us in the future. It argues that while we in the field boped for simple, elegant, and universal theories of negotiation and conflict resolution, the last twenty-five years bave demonstrated the increasing complexification of negotiation theory and practice, from increased numbers of parties and issues, and dilemmas of intertemporal commitments, ethics, accountability, and relationships of private action to public responsibility.

Key words: negotiation, negotiation research, mediation, consensus building, multiparty issues, international conflict resolution.

\section{How It Began}

This journal and the field that spawned it began with a few relatively simple ideas. Solve problems. Look for the underlying interests of those with whom you negotiate. Negotiation is not about maximizing individual gain but about looking for "joint gain" (not the same thing as the overly optimistic "win-win," see Menkel-Meadow 2006a) for all of the parties. Be creative. Find solutions that "expand the pie" and increase what is available before anything has to be divided. Do not assume scarcity of resources or possible solutions. Process matters. Collaborate, do not compete or engage in unnecessary and wasteful compromise either. The process used affects the outcomes achieved. Relationships matter, too - distinguish one-off negotiations from those with ongoing relationships (personal, commercial, or diplomatic). Now we no longer "separate the people from the problem" (Fisher, Ury, and Patton 1991) so easily but take the people and their problems seriously too (Fisher and Brown 1988; Fisher and Shapiro 2005). Get help when necessary - use third-party mediators and facilitators, interview clients and counterparts, and get information from many sources (Menkel-Meadow 2007). Analyze and think before acting. Negotiation and its related conflict resolution processes (mediation, consensus building,facilitation, and now deliberative democracy; Menkel-Meadow 2004/2005) require conceptualization (thinking and analysis), as well as behavior and action. Decision rules and voting procedures matter and should be carefully chosen when trying to reach agreements, depending on the number of parties participating.

From the beginning, Negotiation Journal's stated goal was to make a new kind of journal - one with short, practical essays, research reports, and reviews that would be immediately useful to practitioners and also help to establish the foundations of a new transdisciplinary field. Over the years, many authors returned time and time again to reflect on and refine their ideas and to converse, with each other, in public, about their insights into the processes that both bind us and tear us apart as human beings. 
Although we may have begun with some assumptions about a basic twoparty negotiation to buy goods or services, settle a lawsuit, or even create a peace agreement, we also tried to apply early conceptualizations of a more integrative or problem-solving approach to negotiation to a variety of more complex multiparty and multi-issue settings, as in labor, community, environmental, and international disputes. Over the years, the content in these pages has expanded to offer voice and space to new scholars, practitioners, and teachers as our subjects of interests have moved into new areas - physically, intellectually, and "virtually."

In my admittedly biased view, the Negotiation Journal has not only facilitated development of negotiation and conflict resolution theory, research, practice, and pedagogy, it has also created a diverse, and now international, community of dedicated authors and practitioners devoted to understanding how agreements, decisions, votes, and policies are made, implemented, breached, and enforced so that consensus, rather than command, can govern our behavior and cohabitation of a world with widely diverging interests, values, and preferences. Whether our concepts are universal, ethnocentric, culturally specific, politically motivated, or reflect wishful thinking, whether they are "science" or "ideology" - still remains to be seen, as we continue to think, write, practice, and teach with them in more and more domains.

In this short essay, I reflect on how the Negotiation Journal - and the rapidly expanding field that gave birth to it - has grown to include far more complex theories and applications of negotiation and related conflict resolution processes. My intellectual debt here is to Howard Raiffa (1982, and Raiffa, Metcalf \& Richardson, 2003) who spent his career considering how the numbers of negotiators and issues might complicate and modify some of our elegant, but perhaps overly simplistic, theories and practices. (For example: $n=1$, intrapersonal decisions; $n=2$, bilateral direct negotiations; $n=3$, trilateral or facilitated mediated negotiation and decision making; $n=4$, representational negotiation with two parties; $n=5$, facilitated or multiparty negotiation; $n>5$, complex, larger negotiation or decision-making processes; and $n>100$, differences in substantially larger negotiation or decision making events. ${ }^{1}$ ) Here I want to explore how twenty-five years of theory and practice published on these pages have provided a vast set of teachings, ideas, and practice - what Donald Schön (1983) would call "theory-in-use" - to illuminate our increasingly complex world, which needs all the negotiation theory and practice it can get.

The first volume of Negotiation Journal, which appeared in 1985, introduced many of the basic concepts and processes, for example, interestbased bargaining (Fisher 1985), mediation (Raiffa 1985; Susskind 1985a), new forms of hybrid processes (Henry 1985), and case studies, as well as theoretical insights (Moore 1985), negotiation principles, and examples (Fisher 1985; Raiffa 1985; Susskind 1985b; Zartman 1985). It also elucidated 
some grand purposes, such as "the work of peace" (Urquhart 1985) as well as applications of process observations to particular substantive domains, like environmental and international issues (Carpenter and Kennedy 1985; Lukov 1985). Applications of negotiation and conflict resolution theory to disputes in labor relations, the Middle East, family law, South Africa, nuclear disarmament, hostage taking, and both national and local government decision making and policy planning exemplified, in the early pages of this journal, the wide range of human activities that could be better understood through the systematic study of negotiation processes and searches for interest-based solutions to problems of resource allocation, relationship preservation, contractual relations, and political decision making, among other conflict arenas.

From the beginning there was also an emphasis on pedagogy (e.g., Crohn 1985; Susskind 1985b; Hall 1986; Lewicki 1986) and research and empirical testing of theories (Pruitt 1986; Susskind 1986), as well as the role of ethics in the use of a variety of conflict resolution processes (Fisher 1985; Greenbaum 1986; Lax and Sebenius 1986a). Authors in those first years began to both promote our field and worry about some of the "side effects" of institutionalization (Coulson 1986; Susskind 1986; Adler 1987). The journal published attempts to generate "grand," as well as "middle-level" theory (Avruch and Black 1987). And, in an academic journal that sought to be read both by academics and practitioners - a group that Maria Volpe and David Chandler (2001) have labeled as "pracademics" - many articles were explicitly directed to the development of skills (Fisher and Davis 1987) and to the structuring of new roles and vocations in the field, such as organizational and governmental ombuds (Rowe 1987), facilitators, mediators, and dispute resolution system designers (Ury, Brett, and Goldberg 1988, 1989).

Most importantly, the Negotiation Journal was, from the start, interdisciplinary - recognizing that the insights and knowledge of our new field derived from research, theory, empirical studies, and rigorous analysis in such basic fields as political science, sociology, psychology, economics, and anthropology, as well as more hybrid or applied fields such as game theory, decision sciences, urban planning, law, organizational development, and management (Menkel-Meadow 1983; Bazerman 2005). The reach of articles was local (e.g., Mika 1987) and interpersonal, as well as multicultural and international (e.g., Salacuse 1988) from the start. The journal also explored the resistances to and critiques of our theories, practices, and exhortations to make the world a better place with "interest-based" conflict resolution (see, e.g., Millhauser 1987; Volpe and Bahn 1987).

\section{Where It Went}

Over the years, the subjects of Negotiation Journal articles have expanded to include many different processes, new theories, and evaluation of new 
ideas in research reports, case studies, book reviews, and essays. Negotiation theory has been applied to countless new and previously unimaginable settings, such as nonverbal negotiations among bicycle riders in Beijing (e.g., Faure 1995). We have learned much from theory, practice examples, and reports, both from the field and from research laboratories. Many of the articles that first appeared on these pages are now "classics" and "must reads" for the expanding number of courses and degree programs in conflict resolution, dealing with such varied issues as the role of culture and gender in negotiation, neutrality in mediation and dispute resolution, the role of agents, the use of mediators after a dyadic settlement to "improve" on outcomes reached, comparisons of the behaviors of particular negotiators and mediators, and development of protocols and ethics for particular branches of our field, such as negotiation, mediation, consensus building, or organizational dispute resolution. ${ }^{2}$

Issues treated in these articles have ranged from the descriptive to the prescriptive, drawing from case studies of past negotiations, and suggestions for the proper structuring and conduct of future negotiations or conflict settings. Practitioners have questioned the usefulness of theory, or as Yogi Berra is said to have said, "in theory, theory works, but in practice it doesn't." Development of negotiation and conflict resolution concepts has been inductive and deductive. Modes of conflict resolution have included face-to-face and one-to-one negotiations, as well as media or computerassisted distance negotiations, with the use of facilitators or direct party interaction, as well as treatments of complex multiparty and multi-issue conflicts in both domestic and transnational settings.

A variety of special issues have attempted to generate new transdisciplinary knowledge used to explain negotiation behavior, such as the roles of critical moments (Leary 2004) and improvisation (Balachandra 2005). Whether negotiation theory and behavior can be "universalized" or generalized or rather, vary by context, culture, or gender (Menkel-Meadow 2001; Bohnet and Bowles 2008) has often been explored on these pages. As some conflicts are reported as resolved or at least improved (e.g., elimination of formal South African apartheid), sadly, other conflicts continue to appear year after year as scholars, and practitioners, continue to seek both processes and substantively good outcomes for such intractable and ongoing conflicts as Israel-Palestine (Kelman 1985, 1995; Mnookin 2005; Matz 2006, 2008; Menkel-Meadow and Nutenko 2009) and ongoing iterative labormanagement relations (Crutcher-Gershenfeld et al. 2007).

Negotiation Journal has often encouraged authors to challenge, discuss, and collaborate with each other, in sequential articles, book reviews, or in intentional symposia, as our basic canons have been negotiated on these pages and moved to what some have called "the second generation" (or "Negotiation 2.0") of insights through our practice, teaching, and conceptualizations (Honeyman, Coben, and, De Palo 2009). 


\section{Where Is It Going?}

As the journal moves through its third decade, the founding generation has begun to retire, and a new group of teachers, scholars, and practitioners works to understand more complex negotiation processes, it is useful to reflect on what new challenges we face, with so much knowledge generated about negotiation and conflict resolution, and yet so much conflict remaining in the world (Menkel-Meadow 2006).

In my view, our early hope of creating a transdisciplinary field with simple, elegant, and generalizable principles, applicable to a wide range of diverse contexts, has given way to a more sophisticated understanding of the limits of theories that attempt to universalize in the context of great variations in the locations of conflict and negotiation.

The early years provided a golden age of creative ideas described on these pages and in the books written by many of the first generation (Fisher and Ury 1981; Raiffa 1982; Lax and Sebenius 1986b; Arrow et al. 1995). I can remember my own excitement as a young negotiation teacher and scholar in the 1980s attending faculty colloquia at the Program on Negotiation in which labor-management specialists met with game theorists, law professors, business professors, international relations experts, and urban planners to discover their commonalities in seeking options for mutual gain rather than focusing exclusively on competitive advantage. It seemed a time in which Thomas Schelling's (1960) conflict theories, married to Roger Fisher and William Ury's negotiation principles and Raiffa's mathematical analysis, and informed by applications to labor and international relations, as well as environmental and community disputes, might really generate a "unified field" of theory, applicable to a wide variety of disputes. ${ }^{3}$

In the years that have followed this "golden era," we have witnessed many world events that made it look like at least some of our theories were being used productively. The Berlin Wall came down in 1989, and we expected a more peaceful "cosmopolitan" world, not structured by a bilateral Cold War competitive strategy. Apartheid ended in South Africa without a civil war, and a new form of conflict resolution was born in the Truth and Reconciliation Commissions adapted from prior use in South America to treat past injustices as occasions for healing and movement into a more just future, without violence, retribution, and vengeance. A variety of political movements for increased equality (racial, ethnic, gender, if not economic) gained momentum, as well as some real power, as governments, workplaces, and universities were diversified and opened to more transdisciplinary ideas and fields, including conflict resolution. Children were taught to "use their words" and use peer mediation and other conflict resolution processes to find new ways to deal with each other, as well as adults, teachers, and power holders in their world. 
But new, varied, and sometimes aggressive forms of conflict arose, presenting both theoretical and practical challenges. Feminists and cultural critics challenged the claimed universality of instrumentally focusing on interests, which they saw as utilitarian and/or individual, rather than needs, which they argued are more social in nature (Avruch 2000; Menkel-Meadow 2001) as well as the idea of "inventing options for mutual gain" when there were significant power imbalances between the parties. Researchers also found that negotiators were not always so rational, whether seeking individual advantage or joint gain, and could make serious cognitive, social, emotional, and economic errors when dealing with others (Arrow et al. 1995; Bazerman 2005; see also Tsay and Bazerman 2009 in this issue).

Resources sometimes were scarce (e.g., water, land, finances), and cultural realities sometimes created competing historical narratives, which made achievement of optimistic "pie-expanding" solutions difficult, if not impossible, in such places as Kashmir and Israel-Palestine. The cosmopolitan dream faded as ethnic conflicts broke out in Eastern Europe, new genocides occurred in Africa, and religious differences continued to spawn violence in Asia (e.g., India-Pakistan, Sri Lanka) and the Middle East (e.g., Sunni and Shi'a rivalries), also accompanied by conventional geopolitical, military, tribal, national, and now "viral" conflicts. Some world leaders and other negotiators have refused to engage with us at all, or at least to play by "our" negotiation theories and practices (North Korea), an issue that has plagued our theories since the beginning - how do we negotiate with those who will not "play by our rules" (see Fisher, Ury, and Patton 1991)?

Even in the United States, political parties seemed increasingly uninterested in "getting to yes." Democrats and Republicans produced much unproductive conflict in the 1990s, so much so that an attempt at fostering bipartisan cooperation (in a facilitated "harmony retreat") had to be abandoned as competitive, zero-sum, "gotcha" conceptions of realpolitik continued to mark American governmental processes.

We have come to realize that not everyone negotiates in good faith, and one of the more fruitful avenues of current negotiation theory and practice is to consider when - and even if - we should negotiate at all, and what "preconditions" or deposits of faith or intention we might require before we even begin to develop enough trust to have productive discussions (Mnookin 2003).

We have also learned that in many settings, particularly in legal disputes, what seems like a "two-party" problem is, in fact, much more complicated and often affects many other parties. (Economists refer to these other parties as "externalities," while environmentalists might speak of future generations, insurers are concerned with indemnifiers, intergovernmental bodies will speak of municipalities and states, and divorce mediators consider the impact on children.) We can almost never assume that a 
bilateral agreement of two parties will be sufficient to solve anything but perhaps the most simple buyer-seller agreement.

Many of such core negotiations concepts as BATNAs (best alternative to a negotiated agreement), ZOPAs (zone of possible agreement), trading interests, consent, and commitment, assume that two parties can assess their bargaining zones and find mutually satisfying solutions or better than no-agreement accommodations. As we students of multiparty negotiation now know, when more than two parties are involved, there will be coalition formation, holdouts, vetoes, betrayals, lack of universal consent, and the real possibility that "mutual gains" for some can be very bad losses for others (Susskind et al. 2005). Family, employment, litigation, nation-state, and even interpersonal disputes and relations almost always affect other parties not just those formally represented at the table. Enforcement, legitimacy, credibility, and impacts of negotiated agreements (or breached agreements) are much wider than we originally imagined.

Parties act strategically, and having mastered our "simple" and elegant theories, can manipulate us and use them against us, as when dissembling about needed information or expressing their "true preferences" or desires for trades. Whether we can trust what we are told remains one of the hardest practice problems in negotiation, no matter how much ink is spilled on the subject or complex psychological tests are developed to explore truth telling (Ekman 2004).

Who conducts or manages a negotiation process is now recognized to be far more complex than just two people sitting down and facing each other "across the table." Many negotiations involve representatives with constituency issues and "behind the table" negotiation problems (Mnookin, Peppet, and Tulumello 2000). Or, as we are seeing played out at the moment in the Israeli-Palestinian-U.S. peace process (Abrams 2009), negotiators change over time and the continuity of commitments may become an issue as political regimes change or key negotiators are substituted. We have also learned to never underestimate the power and effects of the personalities of the particular negotiators - an understudied issue in our field (see Curran, Sebenius, and Watkins 2004).

Organizational and governmental negotiations present these issues and more. Layers of hierarchies, authority to commit, moral hazard, displacement to other decision makers, accountability, and transparency versus confidentiality are all issues particular to the types of negotiation that bind more than those specifically sitting at the table. The organizations most dedicated to using our theories - the United Nations, transnational nongovernmental organizations, conflict prevention aid organizations, national truth and reconciliation commissions - are both our best friends and worst enemies when they distort some of the basic precepts we hoped to develop in the early years (e.g., having all stakeholders at the table, using confidentiality to find out what parties really 
want, aiming for true, unanimous consensus). Too often, such institutions seem to believe that they are using our theories and practices but fail to call upon those of us with real expertise in conflict resolution, facilitation, or mediation (Sebenius 1996; Malley and Agha 2001; Carter 2007). Even in the most sophisticated organizational and governmental settings, amateurs (even including career diplomats) do their work (conflict prevention, "handling," or resolution), uninformed by the theory and practice developed by our field. Questions of whether peace should trump justice abound in these settings, with no easy answers (Goldstone 2005/2006; Menkel-Meadow 2006b).

In our well-intentioned efforts to create new, hybrid, and more creative processes such as mediation, consensus building, negotiated rule making, and ombuds in organizations and governments, we have learned that we also need to take account of formal legal requirements (legislative, judicial, or executive body approval, tax consequences), democratic approval of decisions that affect those outside of the negotiation, ethics requirements (both formal and moral), and the need to be transparent about both processes and outcomes. Our imagined and universal "center" will not hold in all contexts.

As the teachings of our interdisciplinary field have proliferated in the last twenty-five years, so have the numbers of those who would profit from their uses. In recent years, we have seen the beneficial effects of the development of a new field called "dispute system design" on efforts to promote dispute resolution in places where disputes occur regularly or iteratively, such as workplaces. We can see new applications of our work in "online dispute resolution" in such settings as e-Bay's successful computerassisted mediation program for millions of sales transactions, as well as in programs addressing internal organizational employment and other disputes (Katsh 2005). However, our theories and practices have also been abused through entrepreneurial overreaching, excessive fees, malpractice, deceptive practices, false promises, conflicts of interests, misuse of confidential information, and other ethical violations in a field (Menkel-Meadow and Wheeler 2004) in which there is no formal ethical monitoring or even a consensus about what might be ethically problematic (Honoroff and Opotow 2007; Menkel-Meadow 2009).

Finally, although Negotiation Journal and other journals in the field have now published many case-study accounts of the successful and unsuccessful use of our theories and practices, we still have little strong empirical evidence (or systematic methods for assessing our own utilities) that our simple, elegant, and founding theories work. It is unclear that we even have a good empirical picture of what negotiators actually do outside of laboratory settings in a wide variety of real-world settings. I am heartened by the fact that empiricists, practitioners, government officials, diplomats, and even journalists, have come to realize that we must have complex, deeply 
textured, and contextually specific ways of conducting our work and evaluating it. We have learned that one size will not fit all. (See, e.g., recent efforts by the conflict resolution-savvy administration of President Barack Obama to distinguish various forms of diplomatic engagement from each other, i.e., engagement with Iran versus engagement with North Korea; Sanger 2009.) But clearly, much more rigorous empirical study of what negotiators and conflict resolvers actually do - and the impacts of what they do - is needed.

So, as the Negotiation Journal and the field that spawned it continue to engage these issues and refine the theories and practices intended to make negotiation a useful human process for creative problem solving, wise and efficient outcomes, and a more peaceful world, I would suggest that scholars and practitioners explore the following extensions of our old and golden theories to the increasingly complex world in which we now find ourselves. Topics for study could include:

1. How do the number of parties affect negotiation principles and practices? Are there particular threshold numbers or levels of participants that have more or less predictable effects on processes (e.g., moving from two to three parties is considered to precipitate a major conceptual and practical leap to coalitional behavior)?

2. How do we determine which parties are even affected by negotiation processes? Those directly involved? Those affected by such processes, without directly participating (e.g., children in divorce, future generations in environmental disputes)?

3. Does the number of issues affect negotiation practices? We often argue that "the more issues the merrier" for exploiting the possibilities of trades and marshalling both conflicting and complementary interests, but what if there are just too many issues to even finalize an agreement (think Israel-Palestine or adding attorneys fees to substantive class action settlements)? When are negotiation issues not all equal or deserving of negotiation with each other? Are all trades fair or equivalent?

4. How do intertemporal negotiations (successor parties, regimes, futures) differ from those with more static time clocks? How do we monitor commitments? What is an intertemporal commitment?

5. How can negotiations proceed among unequals? (This can include at the individual, group, organizational, state, and transnational levels.) Are there successful examples of lasting agreements from unequally endowed parties?

6. When should we negotiate? Do conditions exist under which we should not negotiate (Mnookin 2003)? Are there situations in which "preconditions" are necessary to create trust or good faith insurance? 
(Consider George Mitchell's requirement that weapons in Northern Ireland be decommissioned prior to peace negotiations; Mitchell 1999.) Can we negotiate smaller issues in the middle of larger, more intractable conflicts (Blum 2007)?

7. When are like cases like and unlike cases unlike? This major question of legal jurisprudence - how to treat similar cases fairly and similarly - is a hugely unexplored question of analogical reasoning in our analysis of negotiation situations. Many scholars and practitioners want to compare Northern Ireland to Israel-Palestine; others want to compare the West's current nuclear negotiations with North Korea and Iran. But how do we develop criteria and guideposts for knowing when these situations and cases are more alike or actually quite different from each other?

8. When should we foreswear negotiation and engage in "humanitarian intervention" or war (Stromseth, Wippman, and Brooks 2006)?

9. How do those on behalf of whom negotiators negotiate perceive what negotiators do? Beyond "customer satisfaction," we need more rigorous methods of evaluating the work of negotiators and finding out who their constituencies are, what we have (or have not) achieved for them and for those affected by the agreements we mediate or negotiate.

10. What new combinations of negotiated or other dispute resolution processes are possible? In the years since Negotiation Journal began publishing, we have seen mediation-arbitration (med-arb), negotiated rule making, consensus building, a variety of court-annexed processes such as summary jury trials (Sander 2009 in this issue), national and international truth and reconciliation commissions, as well as a variety of alternative and indigenous judicial-like processes such as the gacaca in Rwanda. What new combinations of our basic processes can we imagine and in what settings?

11. How has a new generation of students - from grade school through professional school - learned about conflict resolution? Can we see any effects of new awareness as they grow into adults and professionals and work in a wide range of fields and settings? At the theoretical level, what more advanced theories can be developed by those who learn the basic principles of our field at ever earlier stages?

12. How will new technologies affect not only the manner but also the content of our negotiated processes? Will enhanced computer and other forms of dispute resolution prove a useful tool in conflict resolution, such as the computer game Peace Maker (Impact Games 2007)? Or will modern communication technology make more violence or less productive social communication (Weimann 2008) more likely? 
13. How can we know what negotiators actually do through empirically studying negotiators and mediators and their clients?

14. And finally, I conclude with the most complex and enduring questions of all. Under what circumstances are human beings more likely to seek productive, negotiated, and consensual agreements with each other? And under what circumstances will they prefer more conventional, traditional, harmful, competitive, and violent ways of seeking advantage? Are negotiation scholars promoting a scientific understanding of human interaction or engaging in wishful or ideological thinking? (Or both?)

It is clear to me that there are many more important questions and issues to explore and study in the future issues of Negotiation Journal. Human beings will always need to negotiate. Let us hope these pages will continue to help current and future generations better understand that human need and process. Happy anniversary to Negotiation Journal and may there be many more.

\section{NOTES}

The author wishes to thank her colleague and dear friend Michael Wheeler for several decades of leadership in the field (and editing of this journal) and dedicates this essay to her friends and intellectual mentors and colleagues at the founding of the Program on Negotiation, from whom she has learned so much, including especially Howard Raiffa, Roger Fisher, Larry Susskind, Deborah Kolb, Frank Sander, Jim Sebenius, the late Jeff Rubin, Bruce Patton, Mary Rowe, and Bill Breslin, among others. Special thanks to Katherine M. Hayes for research assistance beyond the call of duty and to Robert Meadow for support beyond the call of love and forty years of successful relationship negotiations. May the next generation go forth and prosper!

1. Howard Raiffa, and others of us in the field, have often asked whether there were particularly significant threshold levels or numbers of parties or issues that dramatically or substantively change what is possible both in negotiation processes and in possible outcomes to be reached.

2. Some of my personal favorites include Raiffa (1985), Millhauser (1987), Rowe (1987), Rubin and Sander (1988), Touval (1989), Davis (1987), Rubin and Sander (1991), Gadlin (1994), Sander and Goldberg (1994), Gadlin and Pino (1997), Bowling and Hoffman (2000), Avruch (2000), Curran, Sebenius, and Watkins (2004), Susskind et al. (2005), and Susskind (2006).

3. I sought, in my own summary of this path-breaking work, to describe the canonical and cross-disciplinary knowledge it created (Menkel-Meadow 1983).

\section{REFERENCES}

Abrams, E. 2009. Hillary is wrong about the settlements. Wall Street Journal. June 25, 2009, Opinion. Available from http://online.wsj.com/article_email/SB1245887438279505991MyQjAxMDI5NDI1NTgy0.

Adler, P. 1987. Is ADR a social movement? Negotiation Journal 3(1): 59-72.

Arrow, K., R. H. Mnookin, L. Ross, A. Tversky, and R. Wilson. 1995. Barriers to conflict resolution. New York: W.W. Norton.

Avruch, K. 2000. Culture and negotiation pedagogy. Negotiation Journal 16(4): 315-319.

Avruch, K. and P. W. Black. 1987. A generic theory of conflict resolutions: A critique. Negotiation Journal 3(1): 87-96.

Balachandra, L. (ed.). 2005. Special section: Improvisation and negotiation: Expecting the unexpected. Negotiation Journal 21(4): 411-441. 
Bazerman, M. H. (ed.). 2005. Negotiation, decision making and conflict management. Cheltenham, UK: Edward Elgar Publishing.

Blum, G. 2007. Islands of agreement: Managing enduring armed rivalries. Cambridge, MA: Harvard University Press.

Bohnet, I. and H. R. Bowles (eds). 2008. Special section: Gender in negotiation. Negotiation Journal 24(4): 389-508.

Bowling, D. and D. Hoffman. 2000. Bringing peace into the room: The personal qualities of the mediator and their impact on the mediation. Negotiation Journal 16(1): 5-28.

Carpenter, S. and W. J. D. Kennedy. 1985. Managing environmental conflict by applying common sense. Negotiation Journal 1(2): 149-162.

Carter, J. 2007. Palestine: Peace not apartheid. New York: Simon \& Schuster.

Coulson, R. 1986. What can one person do to support dispute resolution? Negotiation Journal 2(4): 329-332.

Crohn, M. 1985. Dispute resolution and higher education. Negotiation Journal 1(4): 310-316.

Crutcher-Gershenfeld, J., T. Kochan, J. P. Ferguson, and B. Barrett. 2007. Collective bargaining in the twenty-first century: A negotiations institution at risk. Negotiation Journal 23(3): 249-265.

Curran, D., J. K. Sebenius, and M. Watkins. 2004. Two paths to peace: Contrasting George Mitchell in Northern Ireland with Richard Holbrooke in Bosnia-Herzegovina. Negotiation Journal 20(4): 513-537.

Davis, A. 1987. The logic behind the magic of mediation. Negotiation Journal 5(1): 17-24.

Ekman, P. 2004. Emotions revealed: Recognizing faces and feelings to improve communication. New York: Henry Holt and Co.

Faure, G. O. 1995. Nonverbal negotiation in China: Cycling in Beijing. Negotiation Journal 11(1): 11-18.

Fisher, R. 1985. A code of negotiation practices for lawyers. Negotiation Journal 1(2): 105-110.

Fisher, R. and S. Brown. 1988. Getting together: Building a relationship that gets to yes. New York: Penguin.

Fisher, R. and W. H. Davis. 1987. Six basic interpersonal skills for a negotiator's repertoire. Negotiation Journal 3(2): 117-122.

Fisher, R. and D. Shapiro. 2005. Beyond reason: Using emotions as you negotiate. New York: Viking.

Fisher, R. and W. Ury. 1981. Getting to YES: Negotiating agreement without giving in. Boston: Houghton Mifflin.

Fisher, R., W. L. Ury, and B. M. Patton. 1991. Getting to YES: Negotiating agreement without giving in, 2nd edn. New York: Penguin.

Gadlin, H. 1994. Conflict resolution, cultural differences and the culture of racism. Negotiation Journal 10(1): 33-48.

Gadlin, H. and E. Pino. 1997. Neutrality: A guide for the organizational ombudsperson. Negotiation Journal 13(1): 17-37.

Goldstone, R. J. 2005/2006. Peace versus justice. Nevada Law Review 6: 421-424.

Greenbaum, M. L. 1986. Resolving conflict without conflicts of interest. Negotiation Journal 2(2): 121-128.

Hall, L. 1986. Preliminary thoughts on graduate programs in dispute resolution. Negotiation Journal 2(2): 207-212.

Henry, J. 1985. Mini-trials: An alternative to litigation. Negotiation Journal 1(1): 13-18.

Honeyman, C., J. Coben, and G. De Palo (eds). 2009. Special section: Second generation global negotiation education. Negotiation Journal 25(2): 141-266.

Honoroff, B. and S. Opotow. 2007. Mediation ethics: A grounded approach. Negotiation Journal 23(2): 155-172.

Impact Games. 2007. Peacemaker. Pittsburgh, PA: Impact Games; Tel Aviv, Israel: The Peres Center for Peace.

Katsh, E. 2005. Online dispute resolution. In The bandbook of dispute resolution, edited by M. L. Moffitt and R. C. Bordone. San Francisco: Jossey-Bass.

Kelman, H. 1985. Overcoming the psychological barrier: An analysis of the Egyptian-Israeli peace process. Negotiation Journal 1(3): 213-234.

- - - 1995. Contributions of an unofficial conflict resolution effort to the Israeli-Palestinian breakthrough. Negotiation Journal 11(1): 19-28.

Lax, D. A. and J. K. Sebenius. 1986a. Three ethical issues in negotiation. Negotiation Journal 2(4): 363-370. 
- - - 1986b. The manager as negotiator: Bargaining for cooperation and competitive gain. New York: Free Press.

Leary, K. 2004. Special section: Critical moments in negotiation. Negotiation Journal 20(2): 143145.

Lewicki, R. J. 1986. Challenges of teaching negotiation. Negotiation Journal 2(1): 15-28.

Lukov, V. 1985. International negotiations of the 1980s: Features, problems, and prospects. Negotiation Journal 1(2): 139-148.

Malley, R. and H. Agha. 2001. Camp David: The tragedy of errors. New York Review of Books 48: 59.

Matz, D. 2006. Reconstructing Camp David. Negotiation Journal 22(1): 89-103.

$-\ldots-$. 2008. When the mediator gets tough. Negotiation Journal 24(4): 533-540.

Menkel-Meadow, C. 1983. Legal negotiation: A study of strategies in search of a theory. American Bar Foundation Research Journal 1983: 905-937.

- - . 2001. Negotiating with lawyers, men, and things: The contextual approach still matters. Negotiation Journal 17(3): 257-293.

- - - 2004/2005. The lawyer's role(s) in deliberative democracy. Nevada Law Journal 5(2): 347-369.

- - - 2006a. Why hasn't the world gotten to yes? An appreciation and some reflections. Negotiation Journal 22(4): 485-503.

- $-.2006 \mathrm{~b}$. Peace and justice: Notes on the evolution and purposes of legal processes. Georgetown Law Journal 94(2): 553-580.

- - . 2007. Know when to show your hand. Negotiation Newsletter 10(6): 1-4.

- - . 2009. Are there systemic ethical issues in dispute system design and what we should (not) do about it. Harvard Negotiation Law Review 14: 1101-1136.

Menkel-Meadow, C. and I. Nutenko. 2009. The next generation: Creating new peace processes in the Middle East. Negotiation Journal 25(4): 567-584.

Menkel-Meadow, C. and M. Wheeler (eds). 2004. What's fair? Ethics for negotiators. San Francisco: Jossey-Bass.

Mika, H. 1987. Mediating neighborhood conflict: Conceptual and strategic considerations. Negotiation Journal 3(4): 397-410.

Millhauser, M. 1987. The unspoken resistance to alternative dispute resolution. Negotiation Journal 3(1): 29-36.

Mitchell, G. 1999. Making peace. New York: Knopf.

Mnookin, R. H. 2003. When not to negotiate: A negotiation imperialist reflects on appropriate limits. University of Colorado Law Review 74: 1077-1107.

- - - (ed.). 2005. The internal Israeli conflict: The past, present and future of the Jewish West Bank and Gaza settlements. Negotiation Journal 21(2): 165-170.

Mnookin, R. H., S. Peppet, and A. Tulumello. 2000. Beyond winning: Negotiating to create value in deals and disputes. Cambridge, MA: Belknap Press of Harvard University Press.

Moore, S. F. 1985. Dividing the pot of gold: Social and symbolic elements in an instrumental negotiation. Negotiation Journal 1(1): 29-44.

Pruitt, D. G. 1986. Trends in the scientific study of negotiation and mediation. Negotiation Journal 2(3): 237-244.

Raiffa, H. 1982. The art and science of negotiation. Cambridge, MA: Belknap Press of Harvard University Press.

- — 1985. Post-settlement settlements. Negotiation Journal 1(1): 9-12.

Raiffa, H., J. Richardson, and D. Metcalfe. 2003. Negotiation analysis: The science and art of collaborative decision making. Cambridge, MA: Belknap Press of Harvard University Press.

Rowe, M. 1987. The corporate ombudsman: An overview and analysis. Negotiation Journal 3(2): 127-140.

Rubin, J. Z. and F. E. A. Sander. 1988. When should we use agents? Direct vs. representative negotiation. Negotiation Journal 4(4): 395-402.

- - 1991. Culture, negotiation and the eye of the beholder. Negotiation Journal 7(3): 249254.

Salacuse, J. W. 1988. Making deals in strange places: A beginner's guide to international business negotiations. Negotiation Journal 4(1): 5-14.

Sander, F. E. A. 2009. Ways of handling conflict: What we have learned, what problems remain. Negotiation Journal 25(4): 531-536.

Sander, F. E. A. and S. B. Goldberg. 1994. Fitting the forum to the fuss: A user-friendly guide to selecting an ADR procedure. Negotiation Journal 10(1): 49-68. 
Sanger, D. 2009. What engagement with Iran and North Korea means. New York Times, June 17, p. 1.

Schelling, T. 1960. The strategy of conflict. Cambridge, MA: Harvard University Press.

Schön, D. 1983. The reflective practitioner: How professionals think in action. New York: Basic Books.

Sebenius, J. K. 1996. Sequencing to build coalitions: With whom should I talk first? In Wise choices: Decisions, games and negotiations, edited by R. Zeckhauser, R. L. Keeney, and J. K. Sebenius. Boston, MA: Harvard Business School Press.

Stromseth, J., D. Wippman, and R. Brooks. 2006. Can might make rights? Building the rule of law after military interventions. New York: Cambridge University Press.

Susskind, L. 1985a. Mediating public disputes. Negotiation Journal 1(1): 19-22.

- - -1985 b. Scorable games: A better way to teach negotiation? Negotiation Journal 1(3): 205-210

- - - 1986. Evaluating dispute resolution experiments. Negotiation Journal 2(2): 135-140.

- - - 2006. Breaking Robert's rules. Negotiation Journal 22(3): 351-355.

Susskind, L., R. H. Mnookin, L. Rozdeiczer, and B. Fuller. 2005. What we have learned about teaching multi-party negotiation. Negotiation Journal 21(3): 395-408.

Touval, S. 1989. Multi-lateral negotiation: An analytic approach. Negotiation Journal 5(2): 159-174.

Tsay, C.-J. and M. H. Bazerman. 2009. A decision-making perspective to negotiation: A review of the past and a look to the future. Negotiation Journal 25(4): 465-478.

Urquhart, B. 1985. The work of peace. Negotiation Journal 1(1): 71-78.

Ury, W. L., J. M. Brett, and S. B. Goldberg. 1988. Designing an effective dispute resolution system. Negotiation Journal 4(4): 413-433.

— - — (eds). 1989. Special section: Dispute systems design. Negotiation Journal 5(4): 357-405.

Volpe, M. R. and C. Bahn. 1987. Resistance to mediation: Understanding it and handling it. Negotiation Journal 3(3): 297-306.

Volpe, M. R. and D. Chandler. 2001. Resolving and managing conflicts in academic communities: The emerging role of the "pracademic." Negotiation Journal 17(3): 245-255.

Weimann, G. 2008. Terror on the Internet. Washington, DC: U.S. Institute for Peace.

Zartman, I. W. 1985. Negotiating from asymmetry: The North-South stalemate. Negotiation Journal 1(2): 121-138. 